\title{
Solving the Puzzle of Global Health Inequity: Completing the Picture Piece by Piece by Piece
}

\author{
Timothy A. Carey ${ }^{1}$ (D)
}

Received: 22 May 2021 / Accepted: 17 August 2021 / Published online: 28 August 2021

(c) The Author(s), under exclusive licence to Springer Nature Switzerland AG 2021

\begin{abstract}
Achieving health equity is an ongoing priority for the global community. Understanding, supporting, and addressing the challenges that face health workers is a critical component of the solution to this problem. The University of Global Health Equity (UGHE) in Rwanda has established the Institute of Global Health Equity Research (IGHER) to contribute to the generation of new knowledge through high-quality research and research training that seeks to improve our understanding of the important issues that influence the distribution of health and healthcare globally. With an unrelenting emphasis on increased impact by prioritizing implementation research, IGHER is particularly interested in amassing a compendium of important research lessons to increase the likelihood that effective implementation strategies will be employed to enhance healthcare service provision. IGHER organizes research according to five foundational research questions, which address different elements that are pivotal to a comprehensive approach to appreciating the nuanced realities of effective healthcare service provision. UGHE outputs for 2020 indicate that: appropriate resourcing of healthcare services is critical for the eradication of global health inequities; policy reform is required for many healthcare innovations and initiatives to be implemented adequately; and high-quality research that is applicable to different contexts is essential for eradicating global health inequities. Furthermore, reimagining healthcare delivery will benefit from an intentional, ongoing, bidirectional influence between evidence-based pedagogy (methods and practices of teaching, education, and instruction) and supporting research activity such that education and instruction inform the research conducted and research findings are fed back to the classroom to help improve education and instruction. As IGHER continues to grow, the valuable insights afforded by high-impact implementation research will increase. These insights will help to inform the development and use of evidence-based implementation strategies for the adoption, scaling, and sustainability of equitable, effective, and efficient health services globally.
\end{abstract}

Keywords Health equity $\cdot$ Pedagogy $\cdot$ Clinical practices and technologies $\cdot$ Health services and systems $\cdot$ Health policy · Implementation science and frameworks

\section{Introduction}

Global health inequities are one of the most urgent dilemmas of the modern era. More than a billion people worldwide have poor health outcomes including unnecessary illness and premature death due to the lack of timely access to affordable, effective, and efficient treatment (Mukherjee, 2018). These disparities exist both within and between countries

Timothy A. Carey

tcarey@ughe.org

1 Institute of Global Health Equity Research, University of Global Health Equity, PO Box 6955, Kigali 20093, Rwanda and incur substantial economic and social costs to individuals, communities, and societies (WHO, 2018).

To advance our knowledge regarding the eradication of global health inequities, this paper has two broad purposes. The first is to describe an innovative and novel approach to organizing research that emphasizes implementation and impact. The approach has been adopted by a new research institute at a new university established to address global health inequities. The second purpose is to synthesize the academic outputs of the university for 2020 to distill the information that has already accumulated for practitioners, university teachers, researchers, and policy- and other decision-makers. For the purposes of this paper, "academic outputs" are regarded as: peer-reviewed published original research; peer-reviewed published reviews and analyses; and 
editorials and op-eds. As the institute continues to grow, accumulated knowledge will incrementally build an increasingly clearer understanding of the factors that are key to eradicating global health inequities. Knowledge such as this will help to intensify implementation efforts as well as research impact.

\section{A New Approach to Addressing Global Health Inequities}

The University of Global Health Equity (UGHE) in Rwanda began contributing to the eradication of global health inequities in 2015 (UGHE, 2017). UGHE's mission is "to radically change the way health care is delivered around the world by training generations of global health professionals who strive to deliver more equitable, quality health services for all." (UGHE, 2017).

\section{The Institute of Global Health Equity Research}

To support the mission of UGHE and amplify the growing impact of its programs, a research institute was established by the university in 2020. Creation of the institute was made possible by a generous donation from the CRI Foundation (https://crifoundation.org) of Andrew and Bonnie Weiss with subsequent funding provided by them to develop a Clinical Trials Center of Excellence within the institute. The Institute of Global Health Equity Research (IGHER) is reimagining the way that research is conceptualized and conducted to accelerate eradication of global health inequities through a focus on implementation and impact. While laying the foundations for a new research institute in the context of a global pandemic such as COVID-19 might not be ideal, information that could provide valuable lessons for practitioners and policymakers is already building. As this information continues to accrue through our own and others' efforts, there will be the opportunity for greater influence on important areas such as the training of future health professionals and the priorities of funding agencies. Advocacy regarding the key lessons synthesized from this approach to organizing research will add value and impact to initiatives aimed at reducing global health inequities.

The vision of IGHER is "A world where research routinely demonstrates tangible and meaningful reductions in global health inequities." In support of the mission of UGHE, the mission of IGHER is "To conduct research and provide research training to change the way healthcare is developed and delivered around the world to eradicate global health inequities." It is beyond the scope of this paper to explore in detail the concepts raised in the vision and mission statements, however, it is important to emphasize that delivering radical change often requires a reimagining of contemporary approaches to the organization and conduct of activity. In the spirit of reimagining research, IGHER has deviated from the standard approach of demarcating research themes according to methodologies such as: randomized controlled trials; epidemiological studies; and cohort studies, or topic areas such as: non-communicable diseases (NCDs); neglected tropical diseases (NTDs); mental health; and public health.

\section{Reimagining the Organization of Research Activity}

Instead of arranging research according to methodologies or topic areas, IGHER's research is organized according to five foundational research questions. These foundational research questions are illustrated in Fig. 1. Each of the foundational research questions focuses on a different but interrelated fundamental component of global health inequities. The foundational research questions are intentionally broad. From these foundational questions, more specific questions pertaining to discrete research projects can be developed. For example, a question such as "Does a standardized checklist improve the rate of adherence to established protocols for newborn care?" could be a specific research question that would help to inform answers to Foundational Research Question Two: "What clinical practices are key to eradicating global health inequities?".

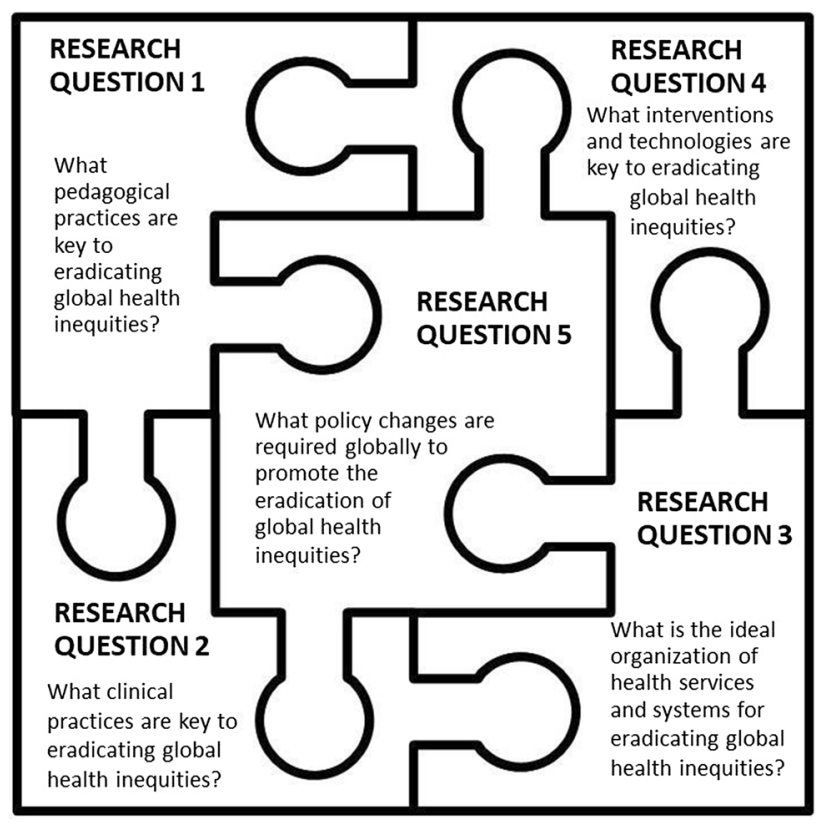

Fig. 1 A systematic approach to the organization of research at UGHE to contribute to the eradication of global health inequities through the articulation of foundational research questions 


\section{Strategic Advantages of Organizing Research According to Research Questions}

Organizing research according to foundational research questions has a number of important strategic advantages. With a system such as this, the primary importance of the research question in the research process is explicitly demonstrated. Moreover, the research questions are constructed to emphasize the priorities of implementation and impact.

When research questions drive research activity there is the opportunity to be nimble and responsive to changing health priorities while still building capacity and expertise in key priority areas. For example, with the COVID-19 global pandemic, areas such as vaccine distribution, public health messaging, social distancing, large-scale testing, and training health workers became urgent priorities. A focus on foundational questions related to areas such as education, clinical practices, and technologies would allow researchers to swiftly reorient their research activity to address these new priorities. With a thematic approach to arranging research, however, the identification of some themes necessitates the exclusion of other themes. If themes are identified based on the expertise of existing Faculty, when those Faculty leave, a gap in expertise will arise creating specific recruitment requirements. For example, if mental health and malaria are identified as two key themes, IGHER would need to ensure Faculty with expertise in these areas were retained. Funding applications also would be restricted to these areas. Focusing on research questions rather than methodologies or content themes, therefore, is broadly inclusive. This approach has none of the restrictive disadvantages of other approaches while introducing several strategic and practical advantages.

Table 1 describes the publications generated by UGHE Faculty in 2020 grouped according to the foundational research question they informed. Some research projects address more than one foundational research question. For example, a research project addressing Foundational
Research Question Three regarding health services and systems, might also provide valuable information for health policy articulated in Foundational Research Question Five. The number of unique publications for each foundational research question are provided in parentheses. For Foundational Research Question One, for example, one original research publication (Bayisenge et al., 2020) addressed both Foundational Research Questions One and Two, and one review publication (Scheiner et al., 2020) addressed Foundational Research Questions One, Two, and Five.

It also is possible to group publications according to distinct health priority areas that may also assist with future planning. Table 2 depicts the various research topic areas for UGHE 2020 publications according to the five foundational research questions. The identified topics were chosen independently by UGHE researchers but have been pooled this way based on the aspect of the topic being addressed. By tabulating the research outputs of UGHE researchers, it is possible to discern where research activity is concentrated and where other efforts could be channelled as further resources become available. Table 2, for example, indicates that currently, the majority of UGHE academic outputs (as they are defined in this paper) are addressing the interventions and technologies as well as the policy research questions and mostly in the areas of mental health and public health.

To help promote the impact of different programs of research, sorting projects according to foundational research questions, enables important lessons to be extracted and synthesized. These lessons can be expanded incrementally as further research is conducted to begin to systematically construct a coordinated and comprehensive understanding of how global health inequities might best be eradicated. Lessons such as these will be helpful in addressing implementation problems that frequently exist in this field.

Table 1 Publications grouped according to publication type with numbers of publications unique to that research question in parentheses

\begin{tabular}{|c|c|c|c|c|c|}
\hline \multirow[t]{2}{*}{ Type of publication } & \multicolumn{5}{|c|}{ Key research questions } \\
\hline & $\begin{array}{l}\text { What pedagogical } \\
\text { practices are key to } \\
\text { eradicating global } \\
\text { health inequities? }\end{array}$ & $\begin{array}{l}\text { What clinical prac- } \\
\text { tices are key to eradi- } \\
\text { cating global health } \\
\text { inequities? }\end{array}$ & $\begin{array}{l}\text { What interventions } \\
\text { and technologies are } \\
\text { key to eradicating } \\
\text { global health inequi- } \\
\text { ties? }\end{array}$ & $\begin{array}{l}\text { What is the ideal } \\
\text { organization of health } \\
\text { services and systems } \\
\text { for eradicating global } \\
\text { health inequities? }\end{array}$ & $\begin{array}{l}\text { What policy changes } \\
\text { are required globally to } \\
\text { promote the eradica- } \\
\text { tion of global health } \\
\text { inequities? }\end{array}$ \\
\hline Original research & $4(3)$ & $6(2)$ & $21(18)$ & $4(4)$ & $1(1)$ \\
\hline reviews and analyses & $4(3)$ & $4(3)$ & $6(6)$ & $5(5)$ & $7(6)$ \\
\hline Editorials and op-eds & $2(2)$ & 0 & $5(5)$ & $6(6)$ & $4(4)$ \\
\hline Total & $10(8)$ & $10(5)$ & $32(29)$ & $15(15)$ & $12(11)$ \\
\hline
\end{tabular}

NB A single publication might contribute to more than one research question 
Table 2 Publications grouped according to health priority area with numbers of publications unique to that research question in parentheses

\begin{tabular}{|c|c|c|c|c|c|}
\hline \multirow[t]{2}{*}{ Type of publication } & \multicolumn{5}{|c|}{ Key research questions } \\
\hline & $\begin{array}{l}\text { What pedagogical } \\
\text { practices are key to } \\
\text { eradicating global } \\
\text { health inequities? }\end{array}$ & $\begin{array}{l}\text { What clinical } \\
\text { practices are key to } \\
\text { eradicating global } \\
\text { health inequities? }\end{array}$ & $\begin{array}{l}\text { What interventions } \\
\text { and technologies are } \\
\text { key to eradicating } \\
\text { global health inequi- } \\
\text { ties? }\end{array}$ & $\begin{array}{l}\text { What is the ideal } \\
\text { organization of health } \\
\text { services and systems } \\
\text { for eradicating global } \\
\text { health inequities? }\end{array}$ & $\begin{array}{l}\text { What policy changes } \\
\text { are required globally to } \\
\text { promote the eradica- } \\
\text { tion of global health } \\
\text { inequities? }\end{array}$ \\
\hline Global surgery & $1(0)$ & $2(1)$ & $4(4)$ & $1(1)$ & $1(0)$ \\
\hline HIV & 0 & 0 & $1(1)$ & 0 & 0 \\
\hline $\begin{array}{l}\text { Community health } \\
\text { and social medicine }\end{array}$ & $1(1)$ & $1(1)$ & $1(1)$ & $1(1)$ & $1(1)$ \\
\hline Mental health & $1(1)$ & $1(0)$ & $7(6)$ & $2(2)$ & $3(3)$ \\
\hline $\begin{array}{l}\text { Nursing and mid- } \\
\text { wifery }\end{array}$ & $1(1)$ & $3(2)$ & $1(0)$ & 0 & $1(1)$ \\
\hline $\begin{array}{l}\text { Maternal and child } \\
\text { health }\end{array}$ & 0 & 0 & $2(2)$ & 0 & $1(1)$ \\
\hline $\begin{array}{l}\text { Health professions } \\
\text { education }\end{array}$ & $3(3)$ & 0 & 0 & 0 & $2(2)$ \\
\hline One health & $3(2)$ & $2(0)$ & $1(0)$ & $1(1)$ & 0 \\
\hline $\begin{array}{l}\text { Health care and health } \\
\text { systems }\end{array}$ & 0 & $1(1)$ & $2(2)$ & $5(5)$ & $2(2)$ \\
\hline $\begin{array}{l}\text { Non-communicable } \\
\text { diseases (NCDs) }\end{array}$ & 0 & 0 & $5(5)$ & 0 & 0 \\
\hline Public health & 0 & 0 & $6(6)$ & $5(5)$ & $1(1)$ \\
\hline Clinical sciences & 0 & 0 & $2(2)$ & 0 & 0 \\
\hline Total & $10(8)$ & $10(5)$ & $32(29)$ & $15(15)$ & $12(11)$ \\
\hline
\end{tabular}

NB A single publication might contribute to more than one research question

\section{Promoting the Link Between Research and the Science of Implementation}

Another benefit to arranging the research activity of an organization according to foundational research questions is that such an approach could establish an explicit and direct link between research activity and implementation science. Fundamentally, implementation science can be understood as the systematic and deliberate investigation of all that is required to achieve effective and sustained practice through the application and integration of research findings (Fixsen et al., 2019; Nilsen, 2015). In the last few decades there has been a proliferation of theories, models, principles, and frameworks as the value of implementation science has been increasingly recognized (Fixsen et al., 2021). Unfortunately, this expansion has led to a fragmentation across disciplines and a lack of coherence in the field (Birken et al., 2017; Fixsen et al., 2021).

To harness the diversity that fragmentation offers, it is possible to embrace the interdisciplinary nature of the field of implementation science by focusing on underlying or core attributes as well as overarching or meta theories and principles. Establishing core competencies in implementation has been one approach to achieving a greater sense of cohesion (Schultes et al., 2021) and another has been the development of a meta or integrative framework. While it is beyond the scope of this paper to explore the diversity of frameworks and models that currently exists, the Consolidated Framework for Implementation Research (CFIR) is a relevant exception. The CFIR is a meta-theoretical framework organized according to constructs related to: the intervention; the inner setting; the outer setting; individuals; and the implementation process (Damschroder et al., 2009).

The CFIR is relevant at all stages of the research process from planning to dissemination and implementation (Birken et al., 2017). In fact, it has been suggested that using the CFIR to assist with research question development could improve the research that is conducted and the subsequent application of the findings (Kirk et al., 2016). The foundational research question approach of IGHER also can contribute to greater conceptual coherence since these foundational research questions are intended to be meta questions from which more specific questions can be formulated to guide specific research projects. Foundational research questions, therefore, also harness diversity across disciplines to triangulate answers to important questions. Using the CFIR alongside foundational research questions can create a bidirectional pathway in which the CFIR assists in the development of specific research questions, and the synthesis of research findings according to foundational research 
questions assists in the refinement and development of CFIR constructs. Table 3 outlines the key findings generated by UGHE scholars for each foundational research question in 2020 along with suggestions of the relevance to CFIR. An asterisk indicates those references addressing more than one foundational research question. The key findings are described in more detail in the following section. The suggestions are not intended to be a definitive or exhaustive list but, instead, are suggestive of the kind of interplay that could occur at this meta level.

\section{Foundational Research Questions}

In this section, the findings produced by UGHE researchers and their collaborators for 2020 are summarized according to each of the five foundational research questions. At the end of each foundational research question section, key learnings are distilled and highlighted along with the relevance to the CFIR and implementation science. In each of the foundational research question subsections, the only research discussed, including the key learnings, is research published by UGHE researchers in 2020. No additional research is included. The details in this section may help illustrate the value of organizing research in this way not only for the particular focus problem such as global health inequities but also for the way this approach might help inform theories, models, principles, and frameworks in implementation science.

\section{What Pedagogical (Educational, Instructional) Practices are Key to Eradicating Global Health Inequities?}

Research and other academic outputs have revealed some key insights in the quest to eradicate global health inequities. While bilateral partnerships between academic institutions in high-income and low- and middle-income countries have the potential to provide unparalleled educational opportunities for both partners, there must be a genuine commitment to ongoing vigilance regarding the intrusion of colonialist perspectives that would retard and ultimately destroy the benefits of the collaboration (Scheiner et al., 2020). Beyond the partnerships that are established, colonialist, racist, and culturally inappropriate and insensitive material can exist in health professions' training curricula (Dudgeon et al., 2020) including the way in which key historical figures, who may have had racist and colonialist beliefs, are portrayed in educational material (Carey et al., 2020a).

The value of a seamless interchange between research and education has been demonstrated regarding the serious but neglected tropical disease, podoconiosis (a type of tropical lymphoedema). Research has identified important gaps in knowledge by health workers as well as insufficiencies in medical school training (Bayisenge et al., 2020; Fowler et al., 2020). Importantly, new knowledge has been generated regarding the demographic profile of podoconiosis patients (Bikorimana et al., 2020), which could inform the development of programs of training and instruction to ensure that training is based on evidence that is current and high-quality thereby helping to reduce inequities in service provision for under-represented diseases.

Patient and healthcare worker safety has been identified as an important focus for training (Kadetz et al., 2020). Once again, research will have a crucial role to play in providing the necessary knowledge to inform the development of such training. Ongoing research also will enable the continued improvement of the training as it is delivered.

The unprecedented situation created by the COVID-19 global pandemic has provided an opportunity to examine ways in which pedagogical practices can be adapted to maintain high-quality standards without compromising access and educational continuity. UGHE has been at the forefront of identifying factors that are key to successfully responding to global pandemics and other emergencies to promote innovation and improved pedagogical effectiveness (Owolabi, 2020; Owolabi et al., 2020a, 2020b). Future research projects can assist in the identification and refinement of pedagogical practices and contexts, including the necessary resources and infrastructure, that are fundamental to successfully developing the next generation of health professionals, leaders, and change-makers. An important but less obvious contribution to effective pedagogical practices are the views and attitudes of the community within which the university is embedded (Kimilu et al., 2020). Building genuine and meaningful engagement with the local community and assessing that engagement by monitoring community perceptions can be an important pedagogical resource to enhance community-based instruction (Kimilu et al., 2020).

\section{Key Pedagogical Learnings}

Colonial and racist attitudes and beliefs are not relics of the past but can be embodied in contemporary academic relationships as well as curriculum material. Constant vigilance is required to identify and correct those perspectives that enable inequities to flourish. High-quality learning experiences can be provided in an online, rather than face-toface format, if key factors are in place such as appropriate learning management systems, context-suited methods of instruction including flipped classrooms, and an appropriate balance of different methods of formative and summative assessment (Owolabi, 2020). When research and education balance and inform each other, students benefit from knowledge that is current, relevant, and high-quality. The CFIR framework topics and constructs associated with this 


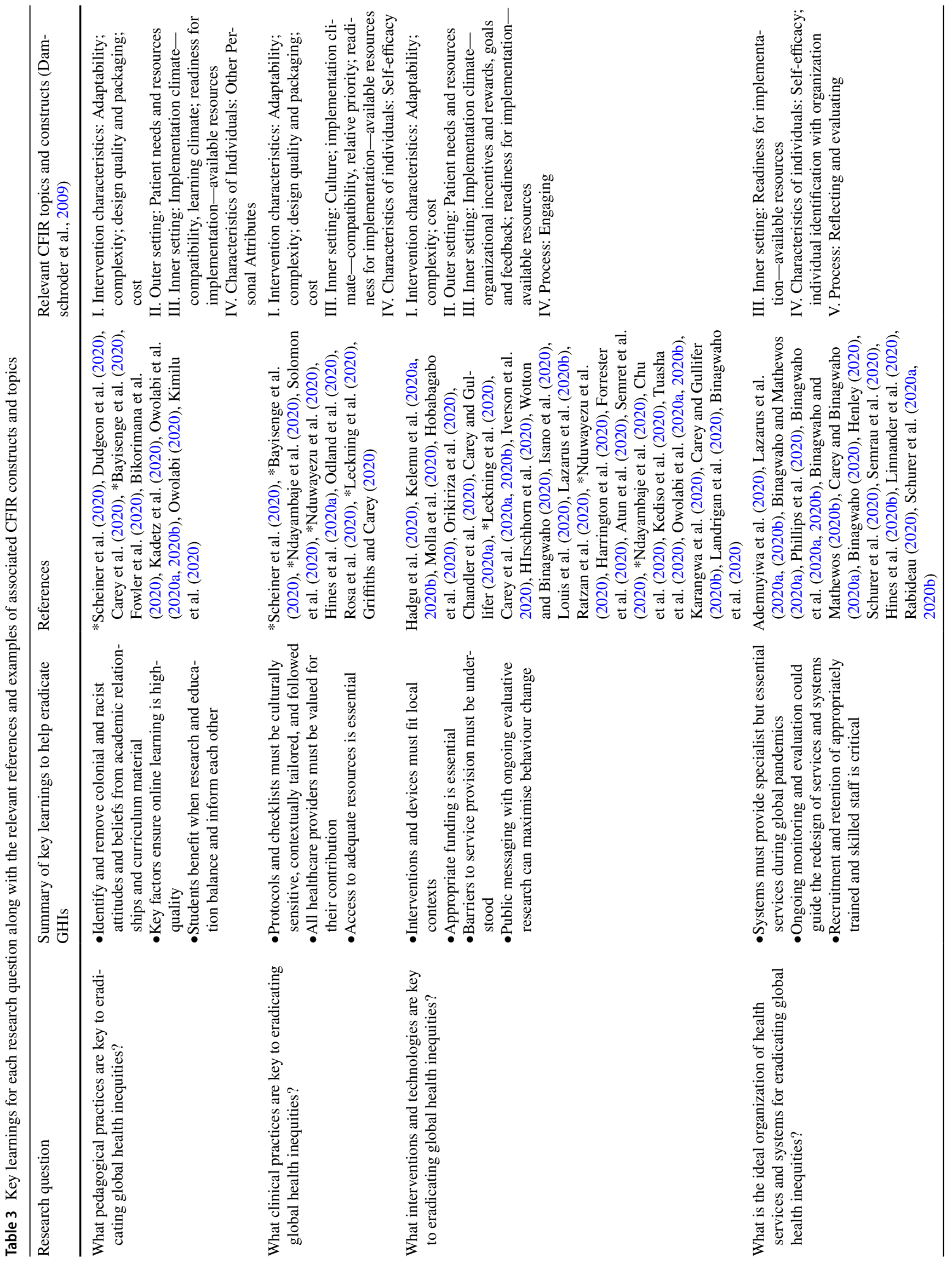


foundational research question (see Table 3) can help to guide future research efforts. For example, the Other Personal Attributes of Characteristics of Individuals indicates that considering traits such as motivation, values, and learning style could further enhance implementation success of educational innovations. These traits might be particularly important when instructional delivery occurs across cultures and different social and economic contexts.

\section{What Clinical Practices are Key to Eradicating Global Health Inequities?}

Greater adherence to clinical guidelines and protocols in areas such as newborn care (Ndayambaje et al., 2020), surgery (Solomon et al., 2020), and snakebite envenomation (Nduwayezu et al., 2020), would assist in the eradication of global health inequities. While adherence might seem like a straightforward matter, it requires both the appropriate training of healthcare professionals and the adequate resourcing of health facilities. One study, for example, found that only $8 \%$ of hospital pharmacies in Rwanda had stocks of snake antivenom during the study period (Nduwayezu et al., 2020). Furthermore, the antivenom in stock was an Indian generic antivenom that was suitable for Asian snakes (Nduwayezu et al., 2020). In another study, supply shortages at some health facilities contributed to low prescription rates of antibiotics in the treatment of podoconiosis (Bayisenge et al., 2020).

Guidelines and protocols for clinical practices should be appropriate for different local contexts and, crucially, should be culturally sensitive (Hines et al., 2020a; Leckning et al., 2020). It also is critical that visiting healthcare providers are aware of local considerations and demonstrate genuine respect for the knowledge, skills, and expertise of resident healthcare workers. A spirit of medical-colonialism can arise, for example, when physicians from high-income countries provide visiting services to health facilities in low- and middle-income countries without due regard to the services already being provided by resident clinicians (Scheiner et al., 2020). Mapping barriers to treatment can be an important first step in enhancing clinical practices and access to high-quality care (Odland et al., 2020).

COVID-19 has highlighted the important roles of different healthcare providers and, in particular, the vital contribution nurses can make in global crises (Rosa et al., 2020b). In a range of different settings, nurses are often at the frontline of healthcare and frequently provide the majority of healthcare services (Rosa et al., 2020b). It is critical, therefore, that the role of nurses is appropriately recognized and adequately resourced to ensure equitable access to their services. Greater theoretical coherence to the core principles and mechanisms that are fundamental to the delivery of care, such as the importance of the patient's perspective and 
inter- and intrapersonal control, could also help to advance nursing, as well as other healthcare worker, practices (Griffiths \& Carey, 2020).

\section{Key Learnings for Clinical Practices}

Clinical practices would assist in the eradication of global health inequities by greater adherence to guidelines, protocols, and checklists that are culturally sensitive and tailored to the local context. The roles of all healthcare providers need to be acknowledged and respected not only by other healthcare workers but also by professional guilds, societies, and organizations as well as health managers and other decision-makers. Healthcare providers need access to adequate resources in order to deliver appropriate and equitable clinical care. The CFIR framework topics and constructs indicates that elements such as an individual's self-efficacy might be an important component of improving implementation efforts. The CFIR also highlights features of the inner setting, such as the implementation climate and the readiness of implementation, could be useful areas for future research efforts. When resources are scarce and equity is compromised, these aspects of implementation might be especially significant.

\section{What Interventions and Technologies are Key to Eradicating Global Health Inequities?}

The importance of contextualizing programs, interventions, and technologies was highlighted in publications that provided contributions and insights regarding the development of an evidence-based answer to the third foundational research question. Variations in genotypes among population groups, for example, can have significant implications for treatment in areas such as breast cancer (Hadgu et al., 2020) and preeclampsia (Kelemu et al., 2020a, 2020b). Important differences also exist in the prevalence of chronic kidney disease (CKD; Molla et al., 2020), abnormal glucose tolerance (Hobabagabo et al., 2020), and in-hospital mortality rates for older adults (Orikiriza et al., 2020).

The development of effective reunification programs for refugee families hinges on appreciating the barriers to reunification across different settings (Chandler et al., 2020). Mental health programs, particularly those being provided in rural, remote, and very remote $(\mathrm{RR} v \mathrm{R})$ settings, would benefit from incorporating locally relevant models of mental health that accommodate cultural beliefs and values (Carey \& Gullifer, 2020a). Cultural understandings may be especially important in the development of guidelines and protocols to assist in areas such as the appropriate assessment of self-harm and suicide attempts in hospital emergency departments (Leckning et al., 2020). When strategies from different cultural traditions are included in existing treatments, a focus on underlying common principles and functional rather the conceptual mechanisms of action may help to improve the effectiveness, relevance, and accessibility of the treatments (Carey et al., 2020b). Adaptations, which attend to local considerations, should not compromise on quality but can configure clinical tools that are locally relevant and meaningful while maintaining metrics that are internationally comparable (Iverson et al., 2020). When selecting and contextualizing interventions, the technology of implementation science can help to ensure the successful application of the interventions (Hirschhorn et al., 2020).

The importance of educational programs and public health messaging in improving engagement with both prevention and treatment strategies is crucial. International comparisons demonstrate the benefits of effective messaging programs as well as the harms of ineffective programs (Wotton \& Binagwaho, 2020). Effective programs of information and education are clearly applicable to the COVID-19 pandemic but also are vital for improving engagement with treatment such as postexposure prophylaxis for men who have sex with men (Isano et al., 2020). Coordinated and systematic national responses during crises such as global pandemics can assist in preventing an escalation of the calamity through, for example, an increase in mental health problems (Louis et al., 2020). A questionnaire has been developed to help governments improve their messaging to promote greater understanding, cooperation, and engagement in public health strategies by the population (Lazarus et al., 2020a, 2020b). Tailored education programs might be particularly useful in situations where new treatments are being introduced such as with the COVID-19 vaccines (Ratzan et al., 2020).

Any discussion about contextualizing interventions to address health inequities cannot ignore the issue of appropriate resourcing. Otherwise successful adaptations, for example, can be undermined by rudimentary problems such as internet connectivity (Harrington et al., 2020). In some situations, healthcare standards can be improved by increasing adherence to adaptive multimodal programmes without infrastructure expenses or resource investments (Forrester et al., 2020). In other areas, however, additional resources must be allocated. For childhood cancers, where the major burden exists in low- and middle-income countries, new funding to scale up cost-effective interventions would alleviate this previously grossly underestimated burden and produce massive health and economic benefits (Atun et al., 2020). Major investments also are needed in laboratory development in low- and middle-income countries so that bloodstream infections that are frequent and often fatal can be prevented through increases in systematic blood culture testing (Semret et al., 2020). Surgical healthcare in sub-Saharan Africa is another area where substantial and sustained investments are urgently needed to correct gross 
inequities (Chu et al., 2020). Additional resourcing also is required to continue developing traditional and plant-based treatments that show promising effects in areas such as epilepsy (Kediso et al., 2020), breast cancer (Tuasha et al., 2020), and the use of skin-lightening creams (Owolabi et al., $2020 \mathrm{a}, 2020 \mathrm{~b})$. Increased resourcing would also allow for the continued development of expanded therapeutic options in the area of the Arts for mental health problems (Karangwa et al., 2020) as well as improving the availability and accessibility of self-care programs to assist in building a resilient mental health workforce particularly in rural, remote, and very remote locations (Carey \& Gullifer, 2020b).

The COVID-19 global pandemic has presented motivating lessons for governments to reorient some of their investment strategies. There is an unprecedented opportunity, for example, to reduce inequities, save lives, and begin to heal the planet by capitalizing on the reduction in ambient air pollution that has arisen during the pandemic (Landrigan et al., 2020). The COVID-19 period also has highlighted the critical need for mechanisms to ensure an equitable global distribution of vaccines (Binagwaho et al., 2020b).

\section{Key Learnings for Interventions and Technologies}

Interventions and technologies need to be developed so that they fit the demands and characteristics of the contexts in which they are to be delivered. In many, but not all, cases, substantial additional funding is required to provide the necessary programs and services. Investments in understanding barriers to service provision also are necessary in some areas. Public messaging is an important means of influencing behavior but evaluative research should be used in an ongoing way to ensure the messaging is achieving the intended results. The framework topics and constructs of the CFIR could be particularly helpful for this foundational research question in assisting to clarify and highlight specific elements for future research investigations. In terms of the outer setting, for example, the CFIR indicates that a more nuanced understanding of patients' needs across diverse contexts, including the barriers and facilitators of need fulfilment could help to enhance implementation efforts.

\section{What is the Ideal Organization of Health Services and Systems for Eradicating Global Health Inequities?}

For health systems and services, the COVID-19 pandemic has provided opportunities, highlighted strengths, and exposed fragilities. Within the context of the global pandemic, for example, there is a major challenge to continue to provide specialist but essential services like surgery (Ademuyiwa et al., 2020). Additional resources have become available such as a Scorecard for governments to review and improve the response of their health system (Lazarus et al., 2020a, 2020b). There have also been repeated calls in combating the virus to learn from past successes (Binagwaho \& Mathewos, 2020a) as well current exemplar countries (Phillips et al., 2020). The value in evidence-based strategies is clear but systems to select and implement the most appropriate strategies are crucial (Binagwaho et al., 2020a). The strength in continental and regional collaboration (Binagwaho \& Mathewos, 2020b; Carey \& Binagwaho, 2020a) and a coordinated, systematic, and sustained response has helped African countries to avert the dire predictions offered at the beginning of the pandemic. By now, the advantages of strong, compassionate, evidence-based leadership (Binagwaho, 2020) characterized by communication, agility, and inclusiveness have been persuasively demonstrated for mitigating the impact of widespread health catastrophes.

Health system reform also needs to be considered outside the context of the current pandemic to address global health inequities. Existing frameworks such as the One Health approach can assist in promoting a greater integration and coordination of services that is clearly necessary and useful for global pandemics (Henley, 2020) but can also assist in the timely and accurate diagnosis of rare but potentially dangerous and even fatal diseases such as human alveolar Echinococcosis (Schurer et al., 2020b). A greater coordination of services would also assist in the effective and timely treatment of comorbidities such as depressive symptomatology with lower limb lymphoedema (Semrau et al., 2020).

System redesign to assist in the eradication of global health inequities clearly requires the successful recruitment and retention of appropriate healthcare workers, which is an international problem in rural, remote, and very remote contexts (Hines et al., 2020b). It is possible, however, to use system-wide interventions to change important elements such as organizational culture and leadership (Linnander et al., 2020). For changes to be effective, responsive, and sustained, decisions regarding system reform should be informed by the genuine and meaningful contributions of all stakeholders including patients (Rabideau, 2020) and Community Health Workers (Schurer et al., 2020a, 2020b).

\section{Key Learnings for Health Services and Systems}

Systems must find ways to continue to provide specialist but essential services during situations such as global pandemics. Ongoing monitoring and evaluation as well as a willingness and commitment to learn from past and current successes could guide the prudent and effective redesign of services and systems. Attention to the recruitment and retention of appropriately trained and skilled staff also is critical to the success of any service. The CFIR provides valuable ways of considering the important learnings in this 
area. For example, with matters of recruitment and retention, effectiveness of implementation initiatives might benefit from consideration of the extent to which an individual identifies with the organization. Perhaps ways of assessing degree of commitment to the organization could provide a useful measure of the likelihood of recruitment and retention success.

\section{What Policy Changes are Required to Promote the Eradication of Global Health Inequities?}

If the innovations and initiatives contributing answers to the first four foundational research questions are to be implemented and sustained, a review of policy directives cannot be ignored. While governments should play a leading role in policy review and redesign, other organizations such as academic institutions can also be at the forefront of policy change. Academic and research institution policies, for example, could promote a rebalancing of research priorities in favour of matters such as research impact (Carey \& Hobabagabo, 2020) as well as the sharing of research outputs through institutional repositories (Wilson et al., 2020). Policies in academic and research institutions could also promote equitable relationships and collaborations between academic institutions in high-income countries and low- and middle-income countries for their mutual benefit (Carey, 2020a; Scheiner et al., 2020).

Policy redesign at the level of government will be pivotal in eradicating global health inequities. Policies insisting on the monitoring and evaluation of services would help to improve both the quality and accessibility of services (Carey, $2020 b$ ). Policies in this area could also provide guidance in terms of decision-making regarding how and what data are collected so that accurate information is available in important areas such as the differential gender impact of global pandemics (Binagwaho \& Yohannes Waka, 2020). Review and reform of policies regarding the recruitment and retention of healthcare professionals (Carey \& Gullifer, 2020c) including the optimal contribution and wellbeing of specific groups such as the nursing workforce (Rosa et al., 2020a, $2020 \mathrm{~b}$ ) will build nimble and responsive teams of healthcare workers.

In areas such as the prevention and treatment of noncommunicable diseases with displaced populations, national policy development is lacking (McNatt, 2020). In other areas, however, including ending child marriages in Nigeria (Obaje et al., 2020), policies have been developed but are not being applied in all jurisdictions. In still other areas, such as the social determinants of health, policies exist but could be refined and nuanced to focus more on common underlying and organizing principles rather than strategies and interventions that may not be applicable and transferable across different contexts and populations (Gullifer et al., 2020).
Policy reform that will be widely applicable will be policy initiatives that depower relationships (Carey \& Binagwaho, 2020b) to enable self-empowerment of individuals, families, and communities to achieve the health outcomes that are important to them rather than empowerment by others.

\section{Key Policy Learnings}

Policy review and reform is required by governments as well as other influential bodies such as academic institutions. Policies can influence the extent to which monitoring and evaluation and other research activity informs healthcare delivery. Recruiting and retaining an appropriately skilled workforce will also be influenced by the governing policy directives. Very few innovations and initiatives designed to eradicate global health inequities can be expected to succeed without the necessary policy support. The CFIR very usefully highlights the importance of policies and guidelines and includes aspects such as benchmarking and external mandates as important considerations. Policy imperatives could be guided by the evidence strength and quality construct of the CFIR and perhaps further research could clarify the various ways in which different stakeholders can influence the outcomes of an intervention.

\section{Concluding Comments}

With an agenda of reimagining healthcare services to eradicate global health inequities, UGHE has established IGHER to systematically coordinate and generate programs of research and research training. Research is organized according to five foundational research questions that allow UGHE researchers to be flexible and responsive according to specific research areas and methodologies according to current priorities, needs, and contexts while also maintaining an unwavering gaze on implementation and impact. Persistently and tenaciously building answers to these questions will illuminate the ways in which global health inequities can be eradicated. The key learnings from the first year of organizing and synthesizing research in this way are summarized in Table 3. Identifying and articulating these key learnings permits them to be incorporated into the process of eradicating global health inequities and also to inform future research directions and priorities. Suggested links to the CFIR meta framework providing some structure to the science of implementation are also provided in Table 3. Connecting the CFIR with foundational research questions enables an increased focus and refinement of specific research questions as well as strengthening the applicability and scope of the CFIR.

Describing current answers to the research questions demonstrates the interconnectedness of the questions as well as the necessity of high-quality, relevant research. Helping 
to improve clinical practices, for example, can involve the use of effective pedagogical strategies to ensure healthcare workers are appropriately trained, and also the necessary resourcing with interventions and devices such as the required medication or the supply of evidence-based, contextualised, checklists and guidelines. It is likely that policy review and redesign will be broadly relevant and applicable. Recognition of the interconnectedness of these research questions is a tremendous advantage in the construction of a sophisticated, sustained, and robust response to global health inequities.

IGHER is seeking to address the challenges of global health inequities by the way it organizes research activity according to foundational research questions and then disseminates this research in terms of key lessons learned. Part of the ambition of IGHER is that publications like this, in journals such as this one, will encourage a focused and sustained global conversation about these and other lessons that can have a lasting impact on global health inequities by enhanced implementation efforts.

As IGHER facilitates and conducts further research and research training, new knowledge will provide additional opportunities to continue efforts at eroding global health inequities. Through these efforts, methodically and incrementally, an exponentially increasing proportion of the global population might begin to enjoy the healthcare and commensurate health outcomes that some people currently experience as routine. An ever-dwindling pool of people forced to endure global health inequities will, ultimately, be of benefit to all through a healthier, more productive, and contented global community.

Data Availability Relevant data and materials are available from the author on request.

\section{Declarations}

Conflict of interest The author declare that he has no conflict of interest.

\section{References}

Ademuyiwa, A. O., Bekele, A., Baraki Berhea, A., Borgstein, E., CapoChichi, N., Derbew, M., Evans, F. M., Feyssa, M. D., Galukande, M., Gawande, A. A., Gueye, S. M., Harrison, E., Jani, P., Kaseje, N., Litswa, L., Mammo, T. N., Mellin-Olsen, J., Muguti, G., Nabukenya, M. T., Ngoga, E., Ntirenganya, F., Rulisa, S., Starr, N., Tabiri, S., Tadesse, M., Walker, I., Weiser, T. G., \& Wren, S. M. (2020). COVID-19 preparedness within the surgical, obstetric and anesthetic ecosystem in Sub Saharan Africa. Annals of Surgery. https://doi.org/10.1097/SLA.0000000000003964

Atun, R., Bhakta, N., Denburg, A., Frazier, A. L., Friedrich, P., Gupta, S., Lam, C. G., Ward, Z. J., Yeh, J. M., Allemani, C., Coleman, M. P., Di Carlo, V., Loucaides, E., Fitchett, E., Girardi, F., Horton,
S. E., Bray, F., Steliarova-Foucer, E., Sullivan, R., Aitken, J. F., Banavali, S., Binagwaho, A., Alcasabas, P., Antillon, F., Arora, R. S., Barr, R. D., Bouffet, E., Challinor, J., Fuentes-Alabi, S., Gross, T., Hagander, L., Hoffman, R. I., Herrera, C., Kutluk, T., Marcus, K. J., Moreira, C., Pritchard-Jones, K., Ramirez, O., Renner, L., Robison, L. L., Shalkow, J., Sung, L., Yeoh, A., \& RodriguezGalindo, C. (2020). Sustainable care for children with cancer: A Lancet Oncology Commission. The Lancet Oncology, 21(4), e185-e224.

Bayisenge, U., Schurer, J., Wong, R., Amuguni, H., \& Davey, G. (2020). Podoconiosis in Rwanda: Knowledge, attitudes and practices among health professionals and environmental officers. PLOS Neglected Tropical Diseases, 14(10), e0008740. https://doi.org/10.1371/journal/pntd.008740

Bikorimana, J. P., Bayisenge, U., Huston, T., Ruberanziza, E., Mbonigaba, J. B., Dukuzimana, M. J., \& Davey, G. (2020). Individual and familial characteristics of patients with podoconiosis attending a clinic in Musanze District, Rwanda: A retrospective study. Transactions of the Royal Society of Tropical Medicine and Hygiene. https://doi.org/10.1093/trstmh/traa068

Binagwaho, A. (2020). We need compassionate leadership based on evidence to defeat COVID-19. International Journal of Health Policy and Management. https://doi.org/10.34172/ijhpm.2020. 73

Binagwaho, A., Frisch, M. F., Ntawukuriryayo, J. T., \& Hirschhorn, L. R. (2020a). Changing the COVID-19 narrative in Africa: Using an implementation research lens to understand successes and plan for challenges ahead. Annals of Global Health, 86(1), 104. https:// doi.org/10.5334/aogh.3001

Binagwaho, A., \& Mathewos, J. (2020a, October 28). Why universal health coverage is the key to pandemic management. Devex. https://www.devex.com/news/opinion-why-universal-health-cover age-is-the-key-to-pandemic-management-98345

Binagwaho, A., \& Mathewos, K. (2020b, November 20). What explains Africa's successful response to the COVID-19 pandemic? Medical News Today. https://www.medicalnewstoday.com/articles/whatexplains-africas-successful-response-to-the-covid-19-pandemic

Binagwaho, A., Mathewos, K., \& Kadetz, P. (2020, December 2). A call for equitable distribution of covid-19 vaccines. The BMJ Opinion. https://blogs.bmj.com/bmj/2020/12/02/a-call-for-equit able-distribution-of-covid-19-vaccines/

Binagwaho, A., \& Yohannes Waka, T. (2020, June 19). Opinion: 'Silent discriminator'-The women global data is leaving behind. Devex. https://www.devex.com/news/opinion-silent-discriminator-thewomen-global-data-is-leaving-behind-97465

Birken, S. A., Powell, B. J., Presseau, J., Kirk, M. A., Lorencatto, F., Gould, N. J., Shea, C. M., Weiner, B. J., Francis, J. J., Yu, Y., Haines, E., \& Damschroder, L. J. (2017). Combined use of the Consolidated Framework for Implementation Research (CFIR) and the Theoretical Domains Framework (TDF): A systematic review. Implementation Science, 12, 2. https://doi.org/10.1186/ s13012-016-0534-z

Carey, T. (2020a, November 28). UN sanctions should not block payments for thesis examining. Times Higher Education. https:// www.timeshighereducation.com/blog/un-sanctions-should-notblock-payments-thesis-examining

Carey, T. A. (2020b). Mental health research and evaluation in rural, remote, and very remote settings. In T. A. Carey \& J. Gullifer (Eds.), Handbook of rural, remote, and very remote mental health. Springer. https://doi.org/10.1007/978-981-10-5012-1_5-1

Carey, T. A., \& Binagwaho, A. (2020a, July 14). Africa: Greatest global challenge is cooperation-Not Covid-19. AllAfrica. Guest Column. Available from https://allafrica.com/stories/2020071500 01.html

Carey, T. A., \& Binagwaho, A. (2020b, July 31). Opinion: We need structural change to enable self-empowerment-Not 
empowerment by others. Devex. https://www.devex.com/news/ opinion-we-need-structural-change-to-enable-self-empowermentnot-empowerment-by-others-97785

Carey, T. A., Binagwaho, A., \& Khanyola, J. (2020, July 9). Beyond Florence Nightingale: How African nurses have decolonised the profession. The Conversation. Accessed on 19 May from https:// theconversation.com/beyond-florence-nightingale-how-africannurses-have-decolonised-the-profession- 141900

Carey, T. A., Griffiths, R., Dixon, J. E., \& Hines, S. (2020). Identifying functional mechanisms in psychotherapy: A scoping systematic review. Frontiers of Psychiatry. https://doi.org/10.3389/fpsyt. 2020.00291

Carey, T. A., \& Gullifer, J. (2020a). Rural, remote, and very remote mental health. In T. A. Carey \& J. Gullifer (Eds.), Handbook of rural, remote, and very remote mental health. Springer. https:// doi.org/10.1007/978-981-10-5012-1_1-1

Carey, T. A., \& Gullifer, J. (2020b). Maintaining control: The importance of self-care to effective and enduring $\mathrm{RR} v \mathrm{R}$ mental health service provision. In T. A. Carey \& J. Gullifer (Eds.), Handbook of rural, remote, and very remote mental health. Springer. https:// doi.org/10.1007/978-981-10-5012-1_23-1

Carey, T. A., \& Gullifer, J. (2020c). The future of rural, remote, and very remote mental health. In T. A. Carey \& J. Gullifer (Eds.), Handbook of rural, remote, and very remote mental health. Springer. https://doi.org/10.1007/978-981-10-5012-1_36-1

Carey, T. A., \& Hobabagabo, A. F. (2020). Assessing impact: Does sample size matter? JBI Evidence Synthesis, 18(12), 243-244. https://doi.org/10.11124/JBIES-20-00443

Chandler, H., Boothby, N., McNatt, Z., Berrigan, M., Zebib, L., Freels, P. E., Alshannaq, H., Majdalani, N., Mahmoud, A., \& Majd, E. (2020). Causes of family separation and barriers to reunification: Syrian refugees in Jordan. Journal of Refugee Studies. https://doi. org/10.1093/jrs/feaa033

Chu, K., Reddy, C. L., Makasa, E., Biccard, B., Bekele, A., Chetty, S., Clune, E., D'Ambrusio, L., Davies, J., Duys, R., Jere, K., Kamalo, P., Levine, S., Lugazia, E., Maswime, S., Muguti, G., Nyaguse, S., Peters, S., Tarpley, J., ... Zorigtbataar, A. (2020). The collateral damage of the COVID-19 pandemic on surgical health care in sub-Saharan Africa. Journal of Global Health, 10(2), 1-5

Damschroder, L. J., Aaron, D. C., Keith, R. E., Kirsh, S. R., Alexander, J. A., \& Lowery, J. C. (2009). Fostering implementation of health services research findings in practice: A consolidated framework for advancing implementation science. Implementation Science, 4, 50. https://doi.org/10.1186/1748-5908-4-50

Dudgeon, P., Carey, T. A., Hammond, S., Hirvonen, T., Kyrios, M., Roufeil, L., \& Smith, P. (2020). The Australian Psychological Society's Apology to Aboriginal and Torres Strait Islander people. In N. Rubin \& R. L. Flores (Eds.), The Cambridge handbook of psychology and human rights (pp. 1818-1866). Cambridge: Cambridge University Press.

Fixsen, A. A. M., Aijaz, M., Fixsen, D. L., Burks, E., \& Schultes, M-T. (2021). Implementation frameworks: An analysis. Active Implementation Research Network. Retrieved August 7, 2021, from https://www.activeimplementation.org/wp-content/uploa ds/2021/04/AIRN-AFixsen-FrameworksAnalysis-2021.pdf

Fixsen, D. L., Van Dyke, M. K., \& Blase, K. A. (2019). Science and implementation. Active Implementation Research Network. Retrieved August 7, 2021, from https://www.activeimplement ation.org/wp-content/uploads/2019/05/Science-and-Implementa tion.pdf

Forrester, J. A., Starr, N., Negussie, T., Schaps, D., Adem, M., Alemu, S., Amemu, D., Gebeyehu, N., Habteyohannes, T., Jiru, F., Tesfaye, A., Wayessa, E., Chen, R., Trickey, A., Bitew, S., Bekele, A., \& Weiser, T. G. (2020). Clean cut (adaptive, multimodal surgical infection prevention programme) for low-resource settings:
A prospective quality improvement study. British Journal of Surgery. https://doi.org/10.1002/bjs.11997

Fowler, K., Wampande, L. N., Gebreselassie, A., Bayisenge, U., Uwase, C., de Oliveira, A., \& Schurer, J. (2020). 'Far from the views of decision-makers': Podoconiosis instruction at medical schools across endemic countries in Africa. Transactions of the Royal Society of Tropical Medicine and Hygiene. https://doi.org/10. 1093/trstmh/traa089

Griffiths, R., \& Carey, T. A. (2020). Advancing nursing practice for improved health outcomes using the principles of Perceptual Control Theory. Nursing Philosophy, 21, e12301. https://doi.org/10. 1111/nup.12301

Gullifer, J., Cibich, M., \& Carey, T. A. (2020). Social determinants of mental health in rural, remote, and very remote contexts. In T. A. Carey \& J. Gullifer (Eds.), Handbook of rural, remote, and very remote mental health. Springer. https://doi.org/10.1007/978-98110-5012-1_2-1

Hadgu, E., Seifu, D., Tigneh, W., Bokretsion, H., Bekele, A., Abebe, M., Sollie, T., Karlsson, C., \& Karlsson, M. G. (2020). Distribution and characteristics of androgen receptor (AR) in breast cancer among women in Addis Ababa, Ethiopia: A cross sectional study. PLoS ONE, 15(5), e0232519. https://doi.org/10.1371/journ al.pone. 0232519

Harrington, C. M., Jang, S. S., Mangaoang, D., O’Flynn, E., Minja, C., Chikoya, L., Bekele, A., \& Borgstein, E. (2020). Integration and sustainability of electronic surgical logbooks in sub-Saharan Africa. World Journal of Surgery. https://doi.org/10.1007/ s00268-020-05613-Z

Henley, P. (2020). COVID-19 and One Health: Shifting the paradigm in how we think about health. JBI Evidence Synthesis, 18(6), 1154-1155.

Hines, S., Carey, T. A., Hirvonen, T., Martin, K., \& Cibich, M. (2020a). Effectiveness and appropriateness of culturally adapted approaches to treating alcohol use disorders in Indigenous people: A mixed-methods systematic review protocol. JBI Evidence Synthesis, 18(5), 1100-1107. https://doi.org/10.11124/JBISR IR-D-19-00040

Hines, S., Wakerman, J., Carey, T. A., Russell, D., \& Humphreys, J. (2020b). Retention strategies and interventions for health workers in rural and remote areas: A systematic review protocol. $J B I$ Evidence Synthesis, 18(1), 87-96. https://doi.org/10.11124/JBISR IR-2017-004009

Hirschhorn, L., Smith, J. D., Frisch, M. F., \& Binagwaho, A. (2020). Integrating implementation science into covid-19 response and recovery. $B M J$. https://doi.org/10.1136/bmj.m1888

Hobabagabo, A. F., Osei-Tutu, N. H., Hormenu, T., Shoup, E. M., DuBose, C. W., Mabundo, L. S., Ha, J., Sherman, A., Chung, S. T., Sacks, D. B., \& Sumner, A. E. (2020). Improved detection of abnormal glucose tolerance in Africans: The value of combining hemoglobin A_1c with glycated albumin. Diabetes Care, 43, 1-7. https://doi.org/10.2337/dc20-1119

Isano, S., Wong, R., Logan, J., El-Halabi, S., \& El-Khatib, Z. (2020). Barriers to post exposure prophylaxis use among men who have sex with men in sub-Saharan Africa: An online cross-sectional survey. Preventive Medicine Reports, 19(101), 100.

Iverson, K. R., Ahearn, O., Citron, I., Garringer, K., Mukhodpadhyay, S., Teshome, A., Bekele, A., Workneh, S., Workneh, R. S., Zemenfeskudus, S., Gultie, T., Varghese, A., Shrime, M. G., Meara, J. G., \& Burssa, D. (2020). Development of a surgical assessment tool for national policy monitoring \& evaluation in Ethiopia: A quality improvement study. International Journal of Surgery, 80, 231-240.

Kadetz, P., Bekele, A., \& Binagwaho, A. (2020, October 14). Training can improve patient and health worker safety in sub-Saharan Africa. The Conversation. Accessed on 19 May 2021 from https:// 
theconversation.com/training-can-improve-patient-and-healthworker-safety-in-sub-saharan-africa-147222

Karangwa, I., Mathewos, K., Ngarambe, B., \& Binagwaho, A. (2020, November 17). The Hamwe Festival explores arts in mental health. The East African. https://www.theeastafrican.co.ke/tea/ sponsored/the-hamwe-festival-explores-arts-in-mental-health3023768

Kediso, T. E., Tolessa, T., Getachew, F., Makonnen, E., \& Seifu, D. (2020). Evaluation of hydro-acloholic extract of Clerodendrum myricoides (Hochst. Vatke) leaves and its solvent fractions in pentylenetetrazole-induced convulsion in mice. Journal of Complementary and Alternative Medical Research, 10(3), 1-10. https:// doi.org/10.97734/JOCAMR/2020/v10i330163

Kelemu, T., Erlandsson, L., Seifu, D., Abebe, M., Teklu, S., \& Storry, S. R. (2020a). Association of maternal regulatory single nucleotide polymorphic CD99 genotype with preeclampsia in pregnancies carrying male fetuses in Ethiopian women. International Journal of Molecular Science, 21(16), 5837. https://doi.org/10. 3390/ijms 21165837

Kelemu, T., Erlandsson, L., Seifu, D., Hansson, E., Abebe, M., Teklu, S., Girma, S., Traherne, J. A., Moffett, A., \& Hansson, S. R. (2020b). Polymorphism in killer cell immunologlubulin-like receptors and human leukocyte antigen-c and predisposition to preesclampsia in Ethiopian pregnant women population. Journal of Reproductive Immunology, 141, 103169. https://doi.org/10. 1016/j.jri.2020.103169

Kimilu, C., Rujema, D., Kalibbala, J., Logan, J., \& Wong, R. (2020). Investigation of community perceptions of a new higher education institute in rural Rwanda. Global Journal of Management and Business Administration, 20(7), Version 1.0, Online ISSN: 2249-4588.

Kirk, M. A., Keley, C., Yankey, N., Birken, S. A., Abadie, B., \& Damschroder, L. (2016). A systematic review of the use of the consolidated framework for implementation research. Implementation Science, 11, 72. https://doi.org/10.1186/s13012-016-0437-z

Landrigan, P. J., Bernstein, A., \& Binagwaho, A. (2020). COVID-19 and clean air: An opportunity for radical change. The Lancet Planetary Health, 4(10), E447-E449. https://doi.org/10.1016/S25425196(20)30201-1

Lazarus, J. V., Binagwaho, A., El-Mohandes, A. A. E., Fielding, J. A., Larson, H. J., Plasencia, A., Andriukaitis, V., \& Ratzan, S. C. (2020). Keeping governments accountable: The COVID-19 assessment scorecard (COVID-SCORE). Nature Medicine. https:// doi.org/10.1038/s41591-020-0950-0

Lazarus, J. V., Ratzan, S., Palayew, A., Billari, F. C., Binagwaho, A., Kimball, S., Larson, H. J., Melegaro, A., Rabin, K., White, T. M., \& El-Mohandes, A. (2020b). COVID-SCORE: A global survey to assess public perceptions of government responses to COVID-19 (COVID-SCORE-10). PLOS ONE, 15(10), e240011. https://doi. org/10.1371/journal.pone.0240011

Leckning, B., Hirvonen, T., Armstrong, G., Carey, T. A., Weslby, M., Ringbauer, A., \& Robinson, G. (2020). Developing best practice guidelines for the psychosocial assessment of Aboriginal and Torres Strait Islander people presenting to hospital with self-harm and suicidal thoughts. Australian and New Zealand Journal of Psychiatry. https://doi.org/10.1177/0004867420924082

Linnander, E., McNatt, Z., Boehmer, K., Cherlin, E., Bradley, E., \& Curry, L. (2020). Changing hospital organisational culture for improved patient outcomes: Developing and implementing the leadership saves lives intervention. BMJ Quality \& Safety. https:// doi.org/10.1136/bmjqs-2019-010734

Louis, E. F., Ingabire, W., Isano, S., Eugene, D., \& Blanc, J. (2020). Rwanda's response during COVID-19. Psychological Trauma: Theory, Research, Practice, and Policy, 12(5), 565-566. https:// doi.org/10.1037/tra0000801
McNatt, Z. Z. (2020). Addressing noncommunicable diseases among urban refugees in the Middle East and North Africa-A scoping review. BMC Conflict and Health. https://doi.org/10.1186/ s13031-020-0255-4

Molla, M. D., Degef, M., Bekele, A., Geto, Z., Challa, F., Lejisa, T., Getahun, T., Sileshi, M., Tolcha, Y., Ashebir, G., \& Seifu, D. (2020). Assessment of serum electrolytes and kidney function test for screening of chronic kidney disease among Ethiopian Public Health Institute staff members, Addis Ababa, Ethiopia. BMC Nephrology, 21, 494. https://doi.org/10.1186/s12882-020-02166-0

Mukherjee, J. S. (2018). An introduction to global health delivery. Oxford University Press.

Ndayambaje, A., Wong, R., Logan, J., \& Kirk, C. (2020). Assessing adherence to the world health organization's essential newborn care guidelines amongst the midwives in a district hospital in Rwanda-A descriptive study. Rwanda Medical Journal, 77(3), $1-6$.

Nduwayezu, R., Kinney, H., Amuguni, J. H., \& Schurer, J. M. (2020). Snakebite envenomation in Rwanda: Patient demographics, medical care, and antivenom availability in the formal healthcare sector. American Journal of Tropical Medicine and Hygiene. https:// doi.org/10.4269/ajtmh.20-0976

Nilsen, P. (2015). Making sense of implementation theories, models and frameworks. Implementation Science, 10, 53. https://doi.org/ 10.1186/s13012-105-0242-0

Obaje, H. I., Okengwu, C. G., Uwimana, A., Sebineza, H. K., \& Okorie, C. E. (2020). Ending child marriage in Nigeria: The maternal and child health country-wide policy. Journal of Science Policy \& Governance. https://doi.org/10.38126/JSPG170116

Odland, M. L., Whitaker, J., Nepogodiev, D., Aling, C. A., Bagahirwa, I., Dushime, T., Erlangga, D., Mpirimbanyi, C., Muneza, S., Nkeshimana, M., Nyundo, M., Umuhoza, C., Uwitonze, E., Steans, J., Rushton, A., Belli, A., Byiringiro, J. C., Bekele, A., \& Davies, J. (2020). Identifying, prioritizing and visually mapping barriers to injury care in Rwanda: A multi-disciplinary stakeholder exercise. World Journal of Surgery. https://doi.org/10.1007/ s00268-020-05571-6

Orikiriza, P., Rukundo, G. Z., Kayanja, A., \& Bazira, J. (2020). Clinical conditions of hospitalized older adult patient and their outcomes in a regional referral hospital in southwestern Uganda. Journal of Aging Research. https://doi.org/10.1155/2020/6830495

Owolabi, J. O. (2020). Virtualizing the school during COVID-19 and beyond in Africa: Infrastructure, pedagogy, resources, assessment, quality, assurance, student support system, technology, culture and best practices. Advances in Medical Education and Practice, 11, 755-759. https://doi.org/10.2147/AMEP.S272205

Owolabi, J., Ames, M., Kiuna, A., Muhire, C., Mojaddam, E., \& Bekele, A. (2020a). Developing models for African tertiary education's response to COVID-19 pandemic and other emergencies: Adapting existing systems, infrastructure and practices for online teaching. Journal of Education, Society and Behavioural Science, 33(10), 59-73.

Owolabi, J. O., Fabivi, O. S., Adelakin, L. A., \& Ekwerike, M. C. (2020b). Effects of skin lightening cream agents-Hydroquinone and kojic acid, on the skin of adult female experimental rats. Clinical, Cosmetic and Investigational Dermatology, 13, 283-289.

Phillips, D. E., Bhutta, Z. A., Binagwaho, A., Boerma, T., Freeman, M. C., Hirschorn, L. R., \& Panjabi, R. (2020). Learning from Exemplars in Global Health: A road map for mitigating indirect effects of COVID-19 on maternal and child health. BMJ Global Health, 5(7), e003430. https://doi.org/10.1136/bmjgh-2020-003430

Rabideau, M. (2020, August 20). Opinion: When incremental change is not enough-Dismantling institutionalized racism in health care systems. Devex, https://www.devex.com/news/opinion-whenincremental-change-is-not-enough-dismantling-institutionaliz ed-racism-in-health-care-systems-97916 
Ratzan, S. C., Binagwaho, A., Larson, H., Lazarus, J., Rabin, K., Gostin, L. O. (2020, October 28). COVID-19: A global survey shows worrying signs of vaccine hesitancy. The Conversation. https://theconversation.com/covid-19-a-global-survey-showsworrying-signs-of-vaccine-hesitancy- 148845

Rosa, W. E., Binagwaho, A., Catton, H., Davis, S., Farmer, P. E., Iro, E., Karanja, V., Khanyola, J., Moreland, P. J., Welch, J. C., \& Aiken, L. H. (2020). Rapid investment in nursing to strengthen the global COVID-19 response. International Journal of Nursing Studies, 109, 103668. https://doi.org/10.1016/j.ijnurstu.2020. 103668

Rosa, W. E., Gray, T. F., Chow, K., Davidson, P. M., Dionne-Odom, J. N., Karanja, V., Khanyola, J., Kpoeh, J. D. N., Lusaka, J., Matula, S. T., Mazanec, P., Moreland, P. J., Pandey, S., de Campos, A. P., \& Meghani, S. H. (2020, June 5). Recommendations to leverage the palliative nursing role during COVID-19 and future public health crises. Journal of Hospice \& Palliative Nursing. https:// journals.lww.com/jhpn/Abstract/9000/Recommendations_to_ Leverage_the_Palliative_Nursing.99880.aspx

Scheiner, A., Rickard, J. L., Nwomeh, B., Jawa, R. S., Ginzburg, E., Fitzgerald, T. N., Charles, A., \& Bekele, A. (2020). Global surgery pro-con debate: A pathway to bilateral academic success or the bold new face of colonialism? Journal of Surgical Research, 252, 272-280. https://doi.org/10.1016/j.jss.2020.01.032

Schultes, M.-T., Aijaz, M., Klug, J., \& Fixsen, D. L. (2021). Competences for implementation science: What trainees need to learn and where they learn it. Advances in Health Sciences Education, $26,19-35$

Schurer, J. M., Tsybina, P., Gesy, K. M., Kolapo, T. U., Skinner, S., Hill, J. E., \& Jenkins, E. J. (2020). Molecular evidence for local acquisition of human alveolar Echinococcosis in Saskatchewan, Canada. The Journal of Infectious Diseases. https://doi.org/10. 1093/infdis/jiaa473

Schurer, J. M., Fowler, K., Rafferty, E., Masimbi, O., Muhire, J., Rozanski, O., \& Amuguni, H. J. (2020a). Equity for health delivery: Opportunity costs and benefits among community health workers in Rwanda. PLoS ONE, 15(9), e0236255. https://doi.org/ 10.1371/journal.pone.0236255
Semrau, M., Davey, G., Bayisenge, U., \& Deribe, K. (2020). High levels of depressive symptoms among people with lower limb lymphoedema in Rwanda: A cross-sectional study. Transactions of the Royal Society of Tropical Medicine and Hygiene, 114, 974-982. https://doi.org/10.1093/trstmh/traa139

Semret, M., Abebe, W., Kong, L., Alemayehu, T., Beyene, T., Libman, M., Amogne, W., Johansen, O. H., Gebretekle, G. B., Seifu, D., \& Yansouni, C. (2020). Prolonged empirical antibiotic therapy is correlated with bloodstream infections and increased mortality in a tertiary care hospital in Ethiopia: Bacteriology testing matters. JAC-Antimicrobial Resistance. https://doi.org/10.1093/ jacamr/dlaa039

Solomon, M., Seyoum, N., Bekele, A., \& Carter, S. (2020). Clinical audit of operation notes at the Department of Surgery, Addis Ababa University. East and Central African Journal of Surgery, 25(1), 13-17.

Tuasha, N., Seifu, D., Gadisa, E., Petros, B., \& Oredsson. . (2020). Solvent fractions of selected Ethiopian medicinal plants used in traditional breast cancer treatment inhibit cancer stem cells in a breast cancer cell line. BMB Complementary Medicine and Therapies, 20, 366. https://doi.org/10.1186/s12906-020-03154-5

UGHE. (2017). Strategic plan FY18-FY22 executive summary. Accessed on 19 May 2021 from http://ughe.org/wp-content/uploa ds/2018/02/UGHE_Strategic-Plan_Executive-Summary_1217.pdf

WHO. (2018). Health inequities and their causes. Accessed on 19 May 2021 from https://www.who.int/news-room/facts-in-pictures/ detail/health-inequities-and-their-causes

Wilson, K., Kiuna, A., Lamptey, R., Veldsman, S., Neylon, C., Hosking, R., Huang, K., \& Ozaygen, A. (2020, April). Open access and research dissemination in Africa. In ELPUB 2020 24th edition of the international conference on electronic publishing. http://doi. org/https://doi.org/10.4000/proceedings.elpub.2020.20

Wotton, L., \& Binagwaho, A. (2020, August 13). Communicating public health and social justice. Project Syndicate: The World's Opinion Page.. https://www.project-syndicate.org/commentary/ communication-uk-rwanda-covid19-crisis-by-laura-wotton-andagnes-binagwaho-2020-08? 